\title{
Varied Ways to Teach the Definite Integral Concept
}

\author{
Iiris Attorps, Kjell Björk, Mirko Radic \\ University of Gävle, Sweden \\ Timo Tossavainen \\ University of Eastern Finland, Finland
}

\begin{abstract}
In this paper, we report on a collaborative teaching experiment based on the Learning Study model (LS model) which grounds on the Variation Theory. Until today, most of such studies have focused on the teaching and learning of elementary school mathematics; ours was carried out in undergraduate mathematics education. In the following, we discuss how we managed to promote students' conceptual learning by varying the treatment of the object of learning (the concept of definite integral and the Fundamental Theorem of Calculus) during three lectures on an introductory course in calculus. We also discuss the challenges and possibilities of the LS model and the Variation Theory in the development of the teaching of tertiary mathematics in general. The experiment was carried out at a Swedish university. The data of the study consists of the documents of the observation of three lectures and the students' answers to the pre- and post-tests of each lesson. The analysis of learning results revealed some critical aspects of the definite integral concept and patterns of variations that seem to be effective to a significant degree. For example, we found several possibilities to use GeoGebra to enrich students' learning opportunities.
\end{abstract}

Keywords: definite integral, GeoGebra, learning study, tertiary education, variation

In Sweden, like in many other countries (Artigue, 2001), the concept of definite integral is first met during the last two years of the upper secondary school. The integral function is usually introduced using the notion of anti-derivative, along the Fundamental Theorem of Calculus connecting the concept of the definite integral with the intuitive idea of area. The theory of integration and the Riemann integrals are systematically discussed only in universities.

Several studies have highlighted difficulties that students encounter with the integral concept. In early studies carried out by Orton $(1983,1984)$, it was noticed that some students have difficulties in solving problems that require capacity to see integration as a limit process of sums. Orton's studies also showed that students interpret the integral sign as a signal "to do something" (cf. Attorps, 2006). Like Orton (1984), also Artigue (2001) found out that although some students' technical ability to calculate definite integrals can be quite impressive, their conceptual understanding of the concept itself may be poor. Similarly, Rasslan and Tall (2002) verified that a majority of the students cannot write meaningfully about the definition of the definite integral. Also many recent studies (e.g., Attorps, 2006; Rösken \& Rolka, 2007; Viirman, Attorps \& Tossavainen, 2011; Tossavainen, Haukkanen \& Pesonen, 2013) concerning the learning of other concepts of calculus have verified that the formal definitions only play a marginal role in students' learning; intuition and non-formal representations dominate their concept learning. For example, Attorps, Björk, Radic and Tossavainen (2010), Blum (2000), Calvo (1997) and Camacho, Depool and Santos-Trigo 
(2010) have verified that students have a strong intention to identify the definite integral with the area of a domain restricted by the integrand and the coordinate axes.

On the other hand, it seems that students' learning of the definite integral can be supported by using graphing calculators in classroom (Touval, 1997). Also Machín and Rivero (2003) noticed that students may benefit from ICT in tasks which concern the graphic and procedural aspects of the definite integral. Nevertheless, the research reports cited above reveal the limitations of standard teaching methods. Although some students become reasonably successful in standard tasks and develop in procedural skills, most of them have difficulties in developing a solid conceptual understanding about the topics itself (Artigue, 2001).

The aim of this study is to investigate whether it is possible, by using technology-assisted teaching (in this case, the dynamic geometric software GeoGebra), to design such teaching sequences of the definite integral concept that help us to improve university students' conceptual understanding of the concept. The theoretical framework for our experiment is based on the Variation Theory which is described in the next section. In its terminology, we seek an answer to the following questions: Which critical aspects of the definite integral concept arise during the lectures? How can we compose effective patterns of variation (of the object of learning) that support students to discern these critical aspects and learn from them?

From a practical point of view, the design of our teaching experiment is that of the Lesson Study model (LS model). The LS model is a synthesis of the Japanese Lesson Study (Lewis, 2002; Stigler \& Hiebert, 1999) and Design Experiments (Brown, 1992; Cobb et al., 2003; Collins, 1992). The LS model goes beyond the Japanese Lesson Study in two major aspects. The first is its theoretical basis: the design of teaching is based on the Variation Theory (Marton et al., 2004). Researchers and teachers work together to establish a framework for the joint inquiry. The second is its method for the evaluation of learning. In the Japanese version, the learners' understanding is evaluated as a long developing process. In the LS model, pre- and post-tests are made before and after every intervention in order to get an immediate conception of what students have learned (see e.g. Runesson, 1999; Häggström, 2008).

The LS model (Marton et al., 2004) makes up a cyclic process as follows:

- A learning study group of teachers determines a common object of learning (in our case the definite integral concept). Previous teaching experiences, theories of concept learning (e.g., Tall \& Vinner, 1981) and results from prior research on the teaching and learning of the object are taken as a starting point for the design of a pre-test.

- Basing on the results of the pre-test, the learning study group plans the first lecture. The Variation Theory is used as a theoretical framework for designing the lecture.

- One of the teachers conducts the first lecture. The lecture is video recorded or observed by the other teachers (in our case, the teacher group made observations). The students' learning is tested in a post-test designed collaboratively.

- Both the test results and the video recordings or the documented observations are analysed by the learning study group. If the students' learning results are not sufficient 
with respect to the goals, the group revises the plan for the same lecture for the next group of students.

- A teacher of the group implements the new plan in another class. In an ideal setting, the cyclic process continues until the students' learning results are optimal.

In our experiment, altogether three researchers participated in the design and analysis of three lessons, a fourth researcher in the analysis of the results.

\section{Theoretical Framework}

The Variation Theory is a theory of learning which is based on the phenomenographic research tradition (Marton \& Booth, 1997). The main idea in the phenomenography is to identify and describe qualitatively different ways in which people experience certain phenomena in the world, especially in an educational context (Marton, 1993).

A significant feature of The Variation Theory is its strong focus on the object of learning. A central assumption is that variation is a prerequisite for discerning different aspects of object of learning. Hence the most powerful didactic factor for students' learning is how the object of learning is represented in a teaching situation. In order to understand what enables learning in one teaching situation and not in another, a researcher should focus on discerning what varies and what remains invariant during a lesson (Marton \& Morris 2001). Marton et al. (2004) have identified four patterns of variation or approaches to discuss the object of learning: contrast, generalization, separation and fusion. The following excerpts illuminate the essence of them:

Contrast: ... in order to experience something, a person must experience something else to compare it with.

Generalization: ... in order to fully understand what "three" is, we must also experience varying appearances of "three".

Separation: ... in order to experience a certain aspect of something, and in order to separate this aspect from other aspects, it must vary while other aspects remain invariant.

Fusion: If there are several critical aspects that the learner has to take into consideration at the same time, they must all be experienced simultaneously. (Marton et al., 2004, 16).

According to Leung (2003), these patterns of variation create opportunities for the students to understand the underlying formal abstract concept.

The object of learning can be seen from various different perspectives: that of a teacher, a student or a researcher. The intended object of learning refers to the object of learning seen from the teacher's perspective. It includes what the teacher says and wants the students to learn during the lecture. The students experience this in their own ways and what they recognize and learn is called the lived object of learning. Obviously, what students' really learn does not always correspond to what the teacher's intention was. The enacted object of learning is observed from the researcher's perspective and it defines what is possible to learn during the lecture, to what extent and in which forms the necessary conditions of a specific object of learning actualize in classroom. The enacted object of learning describes the space of learning that students and teacher create together, i.e., the circumstances for discerning the critical aspects of the object of learning. (Marton \& Tsui, 2004). 
In the Variation Theory, the necessary conditions for learning are the experiences of discernment, simultaneity and variation. Variation is the primary factor to support students' learning. In order to understand what variations a teacher should use, he or she must first become aware of the varying ways students may experience the object of learning. This information is needed for identifying potential ways to help students to discern those aspects of the learning object they have not previously noticed (Marton, Runesson \& Tsui, 2004).

Every concept, situation and phenomenon has particular aspects of their own. If one aspect is varied and others are kept invariant, the varied aspect should arise and be discerned. The thorough understanding of the object of learning, e.g., a mathematical concept, requires the simultaneous discernment of all critical aspects of the object of learning. (Marton \& Morris, 2001; Marton, Runesson \& Tsui, 2004). Consequently, the triangle of discernment, simultaneity and variation can be used also as a framework for analyzing teaching (ibid).

Although the theoretical framework in our study is mostly based on the Variation Theory, we also acknowledge the theory of concept image and concept definition. Tall and Vinner (1981, 152) use the term concept image "to describe the total cognitive structure that is associated with the concept, which includes all the mental pictures associated properties and processes". They suggest that when we think of a mathematical concept, something is evoked in our memory. Often these images do not relate to the formal definition of a concept, i.e., the concept definition, but students prefer to focus, for instance, on the archetypical examples discussing a concept (e.g., Tall, 1994; Viirman, Attorps, Tossavainen, 2011; Tossavainen, Haukkanen \& Pesonen, 2013).

Vinner (1991) claims that the role of definition in mathematical thinking is also neglected in the teaching of mathematics, textbooks and even in the documents about the goals of teaching mathematics. He encourages teachers not only to discuss definitions with students but to train them to use definitions as an ultimate criterion in mathematical reasoning (ibid). The Variation Theory implies that, in addition to typical examples, it is useful also to pay attention to nonexamples of mathematical concepts, even weird ones.

\section{Method}

The study took place at a Swedish university. Altogether 85 first-year undergraduate students (engineering and teacher students) and four university teachers participated in the study. The data consists of photos, observations, notebooks and the video recordings of three lectures in an introductory calculus course. The students' learning was measured using written pre- and post-tests and interviews.

The interviews focused on the participants' understanding about the concept of the definite integral. They were first transcribed and then analysed following a phenomenographic research tradition (Marton, 1993): the main goal is to describe how many qualitatively different conceptions from the certain phenomenon appear rather than to determine how many people who have a certain conception. In our case, the analysis should result in a number of the categories of description, i.e., categories representing the qualitatively different ways in which students comprehend the definite integral concept. (Booth, 1992). 
The pre- and post-tests for measuring students' knowledge about the definite integral and the Fundamental Theorem of Calculus consisted of six problems; the items will be given below. In both tests, the same set of questions was used in order to make the learning outcomes statistically comparable. The maximum of points in each problem was three. To get three points, the answer needed to be correct and well motivated. For minor faults in calculations, we deducted one point. For a correct but not satisfactory motivated answer, we awarded one point. An empty or a meaningless answer resulted in zero points.

Students were given 25 minutes to do the test. The use of any technical facilities like graphing calculators was not allowed. The results were analysed by using a statistic program Minitab.

One can obviously ask whether the observed improvements in the post-tests are due to the familiarity of problems and not a consequence of the implementation of the design of lectures. In order to minimize this effect, we did not reveal the answers or the results of the pre-test to the students. Moreover, they did the post-test without any notice about it in advance. Furthermore, the participating groups were equivalent with respect to their preliminary education; all students were first-year undergraduates from the engineering or teacher programme studying the same introductory course in calculus.

A more detailed description of how we designed and implemented each lesson will be given together with the report on our findings since the design of subsequent lectures was based on the analysis of the previous one(s). The first lecture is to be considered as a reference one. It was prepared without any knowledge of the pre-test results.

The pre- and post-test questionnaire was originally in Swedish. The translations of the items in English are as follows:

Question 1: If you want to calculate the area between the curve and the $x$-axis and the lines $x=0$ and $x=5$ (see the graphs below), you can get an approximate value of this area by calculating and summing the area of each column.

a) Which of the following graphs should you choose in order to make the error as small as possible?

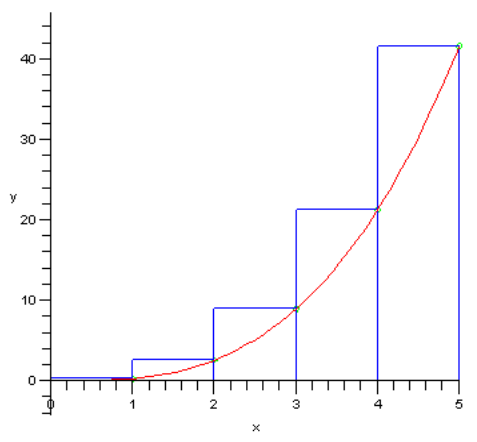

Graph 1

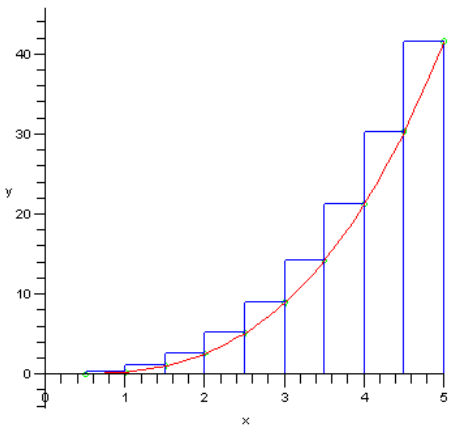

Graph 2

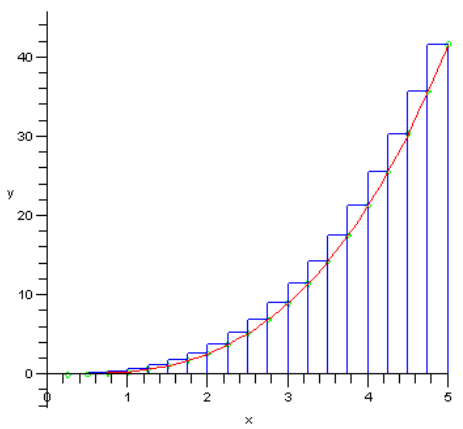

Graph 3

b) Explain your answer.

The aim of the first question was to test a student's intuitive conception or concept image of the exact area as a result of a limiting process (of the upper Riemann sums). By observing 
that the width of each column is halved as we move from the graph 1 to the graph 3 , a student should be able to discern that the area representing the error of approximation also decreases.

Question 2. What does $\int_{a}^{b} f(x) d x$ mean?

The second question aims at measuring whether a student is familiar with the symbol of the definite integral and, if so, what this symbol evokes in his or her concept image of the definite integral.

Question 3. There are some approximate values of $x$ and $F(x)$ given in the table below:

\begin{tabular}{cccccc}
\hline$x$ & 1 & 2 & 3 & 4 & 5 \\
\hline$F(x)$ & -1 & -0.61 & 0.30 & 1.55 & 3.05 \\
\hline
\end{tabular}

Assume now that $F^{\prime}(x)=\ln x$. Approximate the value of $\int_{3}^{5} \ln x d x$.

The purpose of the third question was to test whether this kind of a problem evokes a link to the Fundamental Theorem of Calculus in a student's concept image of the definite integral.

Question 4. Suppose that $\int_{-1}^{5} f(x) d x=2$ and $\int_{-1}^{7} f(x) d x=-1$. Evaluate $\int_{5}^{7} f(x) d x$.

This question tests whether a student can apply the additive properties of the definite integral.

Question 5. Can you find any error in the following reasoning?

$$
\int_{-1}^{1} \frac{d x}{x^{2}}=\int_{-1}^{1} x^{-2} d x=\left[\frac{x^{-1}}{-1}\right]_{-1}^{1}=\frac{-1}{1}-\frac{-1}{-1}=-2
$$

The aim of the fifth question was to examine whether a student have a correct conception about the prerequisites for applying the Fundamental Theorem of Calculus.

Question 6. Find the area of the region limited by the functions $f(x)=0.5 x^{2}$ and $g(x)=x^{3}$.

Give the exact value of it.

The idea of the last question was to test the students' procedural skills in applying the Fundamental Theorem of Calculus.

In the next section we are going to present the results of our study which consisted of three lectures on the same topic. The first lecture is to be considered as a reference one. It was prepared without any knowledge of the pre-test results. The second and the third lectures were designed on basis of the information of the post-test results of the first and the second lecture respectively. Having this information available, we revised the patterns of variation of the observed critical aspects of the object of learning in lecture two and three. 


\section{Results}

The analysis of our findings follows the hypothesis of Marton and Morris (2002) and Marton and Tsui (2004) that different patterns of variation create different learning opportunities. Therefore, we begin by illuminating the progression of each lecture.

\section{Lecture One}

The first lecture (LS1) was designed by the first lecturer alone, without having any prior knowledge of the pre-test results. Two researchers observed the lecture. The first group is therefore to be considered as a reference group; it consisted of engineering students only.

The lecture started with a discussion about the area concept and how to calculate the area of common figures such as rectangles, triangles and parallelograms. For example, the area of a circle was estimated by transforming the circle into a parallelogram. It was done by cutting the circle into wedges which were then organized into the shape of a parallelogram. As the number of wedges increases, the area of the parallelogram approaches to the area of the original circle.

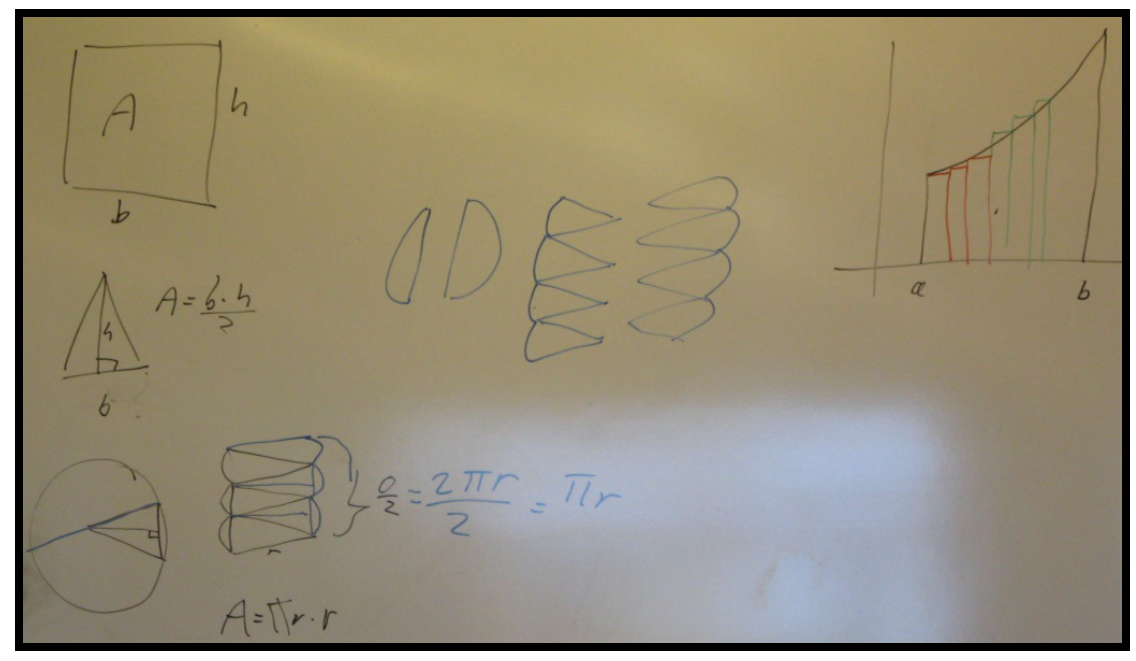

Figure 1. The transformation of a circle into a parallelogram.

The lecture continued with a discussion about how to calculate areas for irregular regions such as an area between an arbitrary continuous function and the x-axis. In this context, the sigma symbol (summing) and the concepts of Lower and Upper Riemann sums were introduced. The end of the lecture was spent on demonstrating how to proceed when calculating an area of the plane region lying above the $x$-axis and under the curve $y=e^{x}$, i.e., $\int_{0}^{1} e^{x} d x$

The problem was studied first in terms of Lower and Upper Riemann sums and the limiting process and then solved by applying the Fundamental Theorem of Calculus. In discussion, the conditions for applying the theorem were not mentioned explicitly. After the lecture, the students answered the post-test anonymously. 


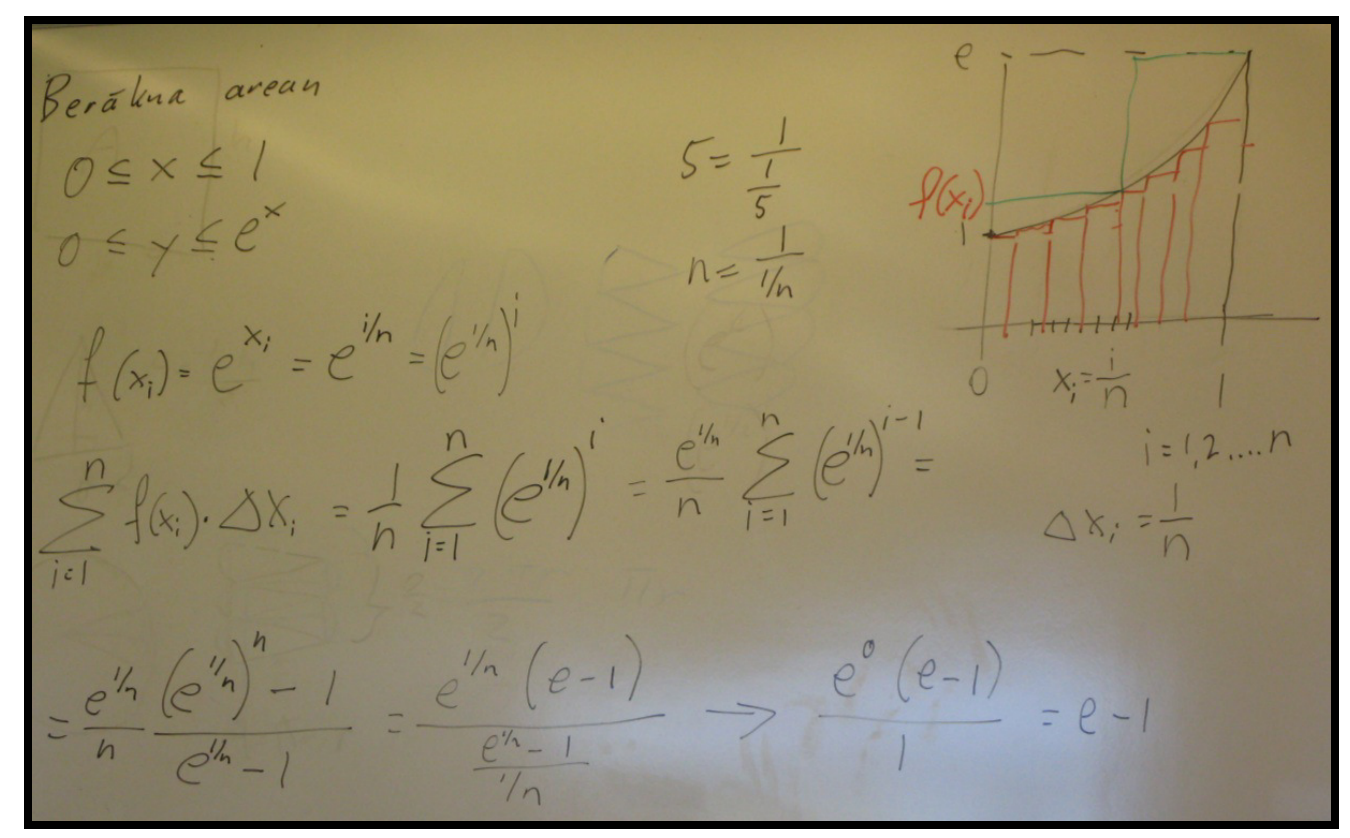

Figure 2. The calculation of area using the Riemann sums and the limiting process.

\section{Lecture Two}

Before designing the second lecture, we decided that, in order to improve the precision of our statistical evaluation, we should compare the results of the pre- and post-test in the subsequent learning studies LS2 and LS3 at the individual level instead of the group level as was the case in LS1. Furthermore, we decided to videotape our next lectures.

Before the second lecture, we carefully analysed the observations and the results of the post-test. The results in Table 1 summarize the learning results of the first group. In a more thorough inquiry to LS1, we could identify the following three critical aspects.

First, we noticed that most of the students, who answered the second question, had interpreted the definite integral in Question 2 merely as an area and not as a real number that can have negative, zero or positive value. Second, the results both in the pre- and post-tests indicated that the students have difficulties in discerning the correct conditions for applying the Fundamental Theorem of Calculus, especially in the case when it is not possible (Question 5). Third, a large majority of the students failed in solving the ordinary routine exercise (Question 6). For example, they could not decide which one of the functions represents the upper or lower function or determine the intersection points between the functions. Some of them even had problems with the arithmetic of fractions.

Having this information available, we revised the patterns of variation of these three critical aspects in the next lectures so that the correct aspect should be easier to discern. For example, we decided to emphasize the formal definition of the definite integral and the fact that it cannot always be interpreted as an area. Further, students should pay more attention to the conditions of theorems to be applied.

The second lecture was carried out by a teacher in the research group to a mixed group of engineering and teacher students. The second lecture started with a discussion about the concept of area and regular (polygonal) and irregular regions in the plane. After that, the 
definite integral concept was introduced and discussed through a typical example from upper secondary school: $\int_{0}^{2}\left(2 x-x^{2}\right) d x$. Also the geometric interpretation of the problem was illustrated and the problem was solved using the Fundamental Theorem of Calculus emphasizing the conditions for applying it. Then another variant of the same problem was discussed graphically by studying the functions $f(x)=2 x$ and $g(x)=x^{2}$, see Figure 3 . Further, using two different approaches to solve the same problem, we especially aimed at the experiences of generalization and separation.

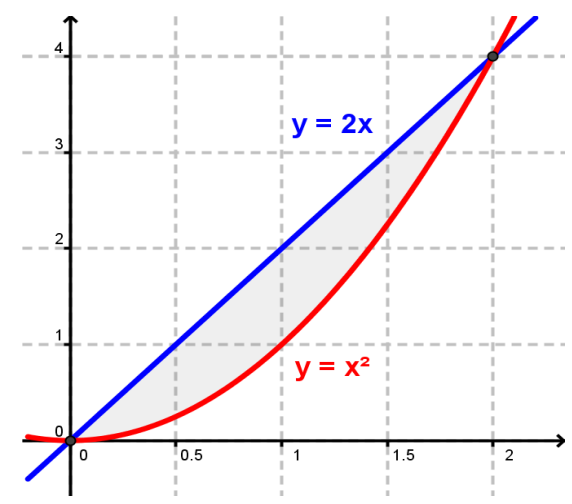

Figure 3. The illustration of the upper and lower functions.

The concepts of the upper $(f(x)=2 x)$ and lower $\left(g(x)=x^{2}\right)$ functions were introduced in this connection. We also recalled how to find the intersection points of the functions. After that, the second lecture continued similarly as the first one with discussions about how to find the area by using estimation (Lower and Upper Riemann sums) and the limiting process for arbitrary irregular regions above the $x$-axis. However, in order to show how to interpret the definite integral in the general case (i.e. not only as an area), the following example was considered thoroughly.

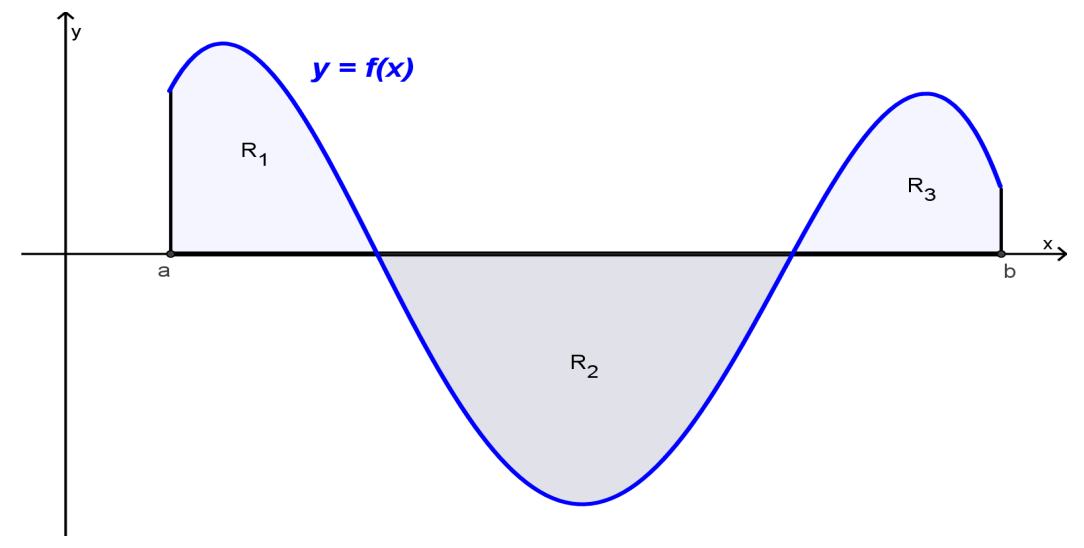

Figure 4. $\int_{a}^{b} f(x) d x=$ area $\mathrm{R}_{1}-\operatorname{areaR}_{2}+\operatorname{areaR}_{3}$.

By constructing an example where the definite integral of a function had a negative value, we emphasized the experience of contrast. 
In the end of the lecture, the example of $\int_{0}^{2} \frac{1}{x-1} d x$ was examined graphically reflecting on the necessary conditions for applying the Fundamental Theorem of Calculus.

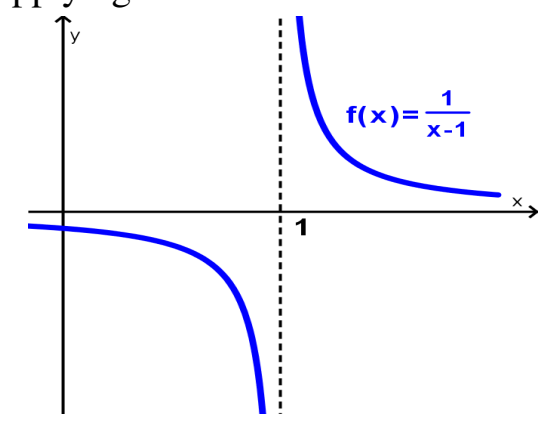

Figure 5. The graph of the function $f(x)=\frac{1}{x-1}$.

In order to stress the importance of the necessary conditions for applying the Fundamental Theorem of Calculus, here we emphasized the experiences of separation and fusion.

\section{Lecture Three}

The test results (Table 2) for the second group of engineering and teacher students revealed that students' understanding about the concept of definite integral was still inadequate although some statistically significant improvements were observed. Most of the students interpreted the definite integral again only as an area. Similarly, the problems related to the conditions for applying the Fundamental Theorem of Calculus (Question 5) remained actual; likewise the problems in solving the ordinary routine exercise (Question 6). In order to gain a more detailed view of students' conception of the definite integral, we interviewed five students from the second group. The analysis of the interviews revealed three different categories of description: the definite integral is seen as 1) a limiting process, 2) an area or 3) a procedure.

The first category represents those students whose conceptions of the definite integral focus on a limiting process, the approximation of the area of a curvilinear region by breaking it into thin vertical rectangles. One of the students describes the process in the following way: "The error decreases the closer the infinite the number of columns are nearing. The columns will look like the curve more and more." This excerpt and the test results from lectures one and two indicated that some students have a relatively good intuitive understanding about the definite integral as a limiting process.

For the students in the second category of description, the definite integral $\int_{a}^{b} f(x) d x$ stands for the area between $\mathrm{f}(\mathrm{x})$ and $\mathrm{x}$-axis. "It is an area between $y=0$ and $y=f(x)$ in the interval $[a, b]$ " as one of the students explained in the interview. Most of the students in this study described the definite integral in the pre- and post-tests in this or a similar way.

The students belonging to the third category viewed the definite integral as a procedure. For them, the definite integral seems to be merely a formula and they use procedures without considering definitions and theorems when solving problems related to that. One of the 
interviewed students described his conception in the following way: "This I had to learn in upper secondary school. You write down the primitive function with brackets. I take the values of the end point minus the starting point, then it's just a simple subtraction". Another student said, when looking at Question 5, "It looks like an ordinary integral calculation. That is correct... "

The weakest students of the study fell typically into this category. These students mentioned in interviews that theorems were not much discussed from a theoretical point of view in upper secondary school. Theorems were applied more like formulas.

Taking into account the results from the pre- and post-tests and the interviews we again revised our plan for the next lecture. The most notable difference between the third and the previous lectures is that we decided to use the free dynamic mathematics software GeoGebra for the illustration of critical aspects.

The third lecture was given by the same teacher as the second one but now to a new group consisting of only engineering students. It began with a short discussion about how to find an area for a (polygonal) regular and an irregular region lying above the $x$-axis.

The first exercise with GeoGebra (see Figure 6) focused on the numerical approximation of the area as the Lower and Upper Riemann sums and the definition of the definite integral as the limiting process. In Figure 6, two points, $a$ and $b$, are shown and they can be moved along the $x$-axis in order to modify the investigated interval. The values of the Upper and Lower sums together with their difference are displayed as a dynamic text automatically adapting to the modifications. In this exercise, we kept $f(x)$ and the interval invariant and varied the number of subintervals. Our intention was to show that, by increasing the number of subintervals, the difference between the lower and upper sums can be made to decrease, suggesting that the lower and upper sums eventually coincide with the value of the definite integral. By utilizing GeoGebra we created the pattern of generalization dynamically.
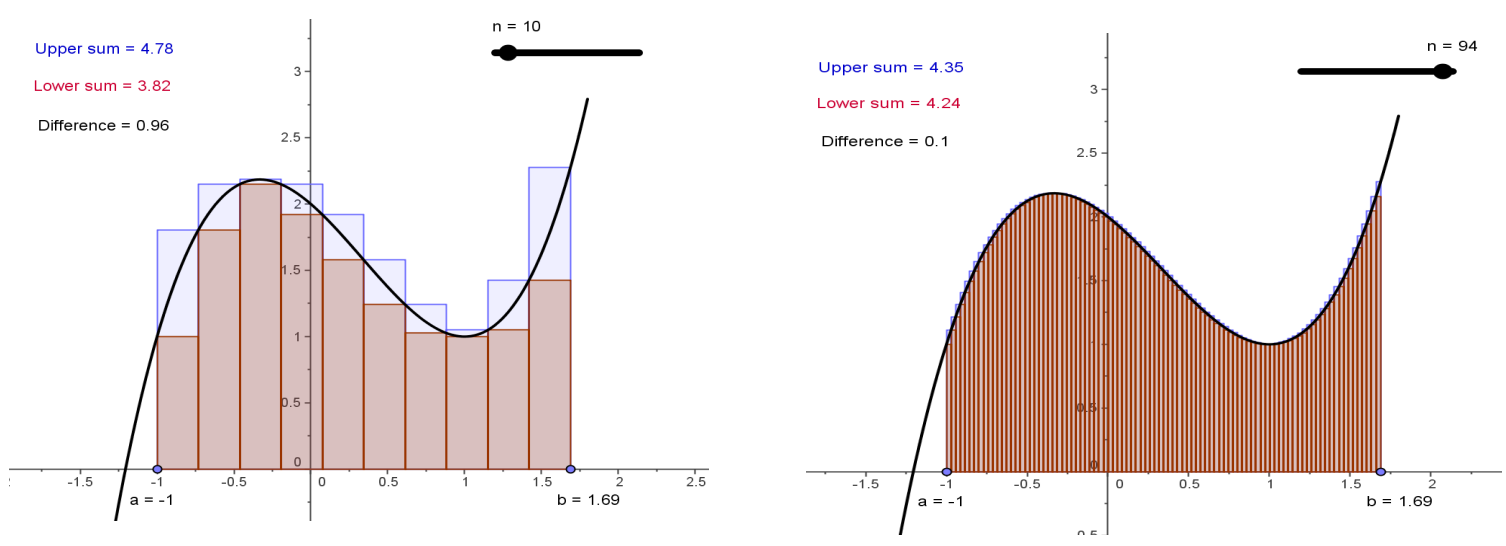

Figure 6. The Lower and Upper Riemann sums and the inherent infinite processes.

After this, the same problem as shown in Figure 3 was solved. It was also highlighted that when applying the Fundamental Theorem of Calculus for $\int_{0}^{2}\left(2 x-x^{2}\right) d x$, the function $y(x)=2 x-x^{2}$ must satisfy the following assumptions: it must be a defined, continuous and nonnegative function on the closed interval $[a, b]$. The following two figures demonstrate how we illustrated the conflict between the definition of the definite integral 
concept and the area interpretation of it. GeoGebra gave us a good opportunity to dynamically demonstrate contrast, which was one of the patterns of variation.

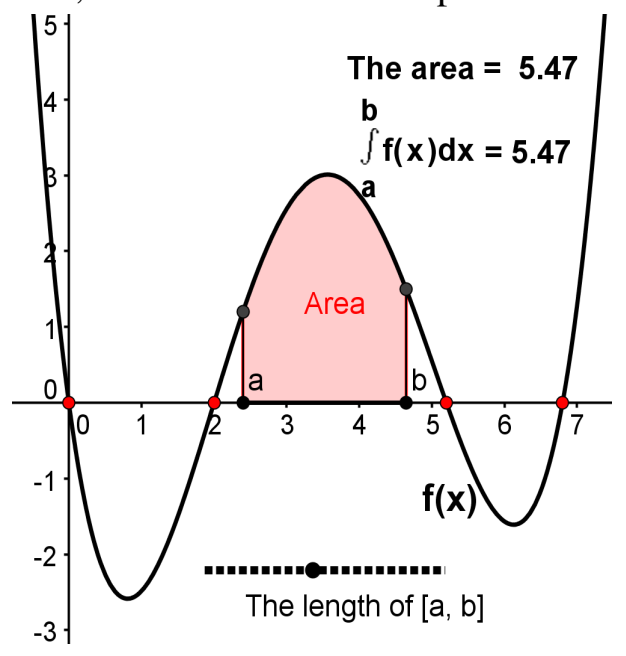

Figure 7. The value of the definite integral is now identical to the area between function and $x$-axis in the interval $[a, b]$.
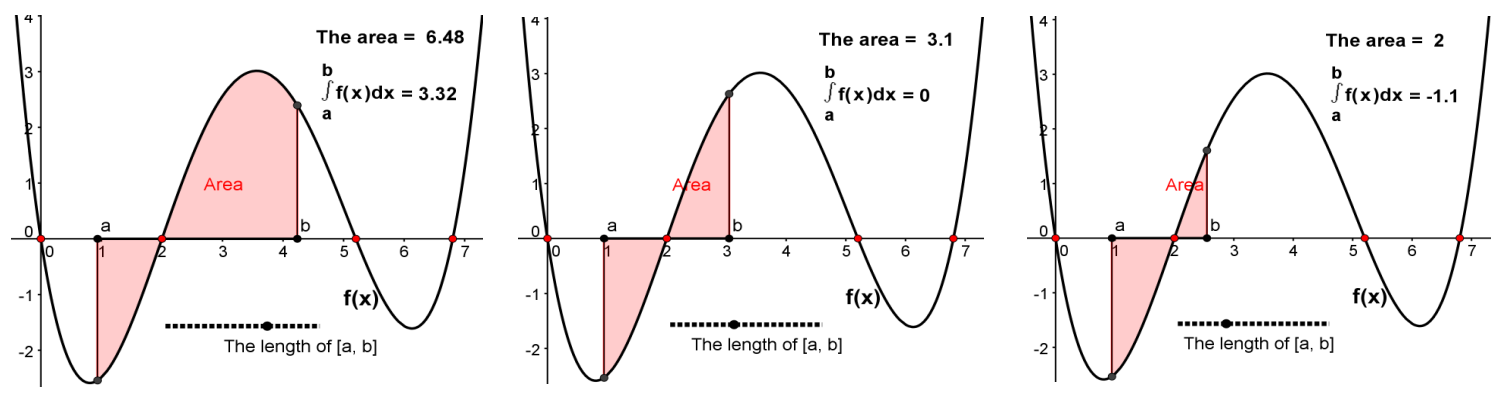

Figure 8. The definite integral results in a real number which can be positive, zero or negative.

In the second GeoGebra application related to Figures 7 and 8, two points, $a$ and $b$, are shown so that they can be moved along the $x$-axis. The area and the value of the definite integral are displayed as a dynamic text. In this exercise, we kept only $f(x)$ invariant and varied both the length of the interval and the upper and lower limit points in order to show that the values of the area between the function and the $\mathrm{x}$-axis and the definite integral do not always coincide. Our goal with the third exercise (Figure 9) was to help the students to discern situations where it is possible to apply the Fundamental Theorem of Calculus and to notice when it is not. 

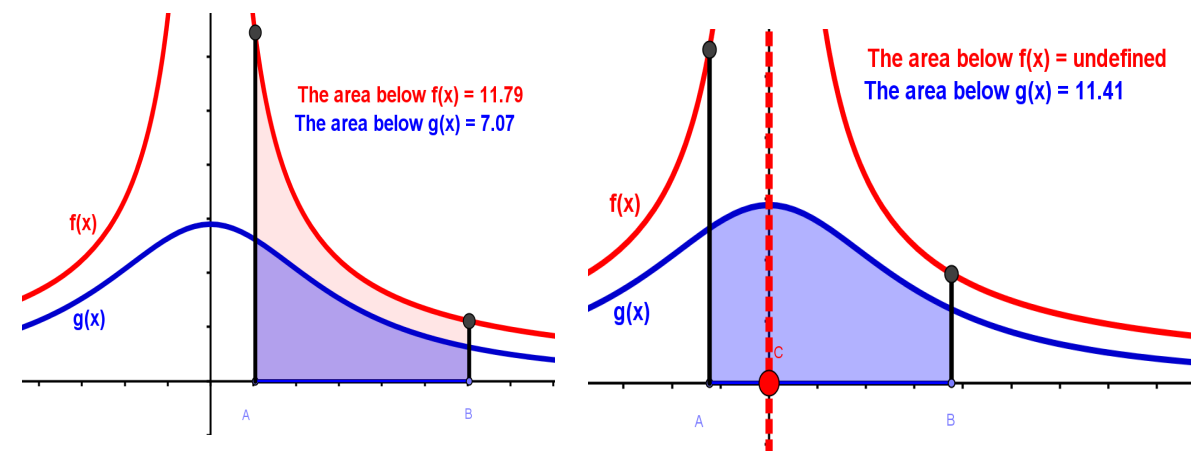

Figure 9. The illustration of the conditions of the Fundamental Theorem of Calculus.

By moving the point A along the $x$-axis, we can vary the position of the investigated interval. In this exercise, we kept the length of the interval and the functions $f(x)$ and $g(x)$ invariant and varied the location of the point A. By using the dynamic nature of GeoGebra we were able to demonstrate all the aspects of variation, i.e. contrast, generalization, separation and fusion. In the end of the third lecture, the same problem $\left(\int_{0}^{2} \frac{1}{x-1} d x\right)$ as shown in Figure 5 was studied.

\section{Quantitative Analysis of the Pre- and Post-Tests}

We analysed the scores of the pre- and post-tests with the Minitab software using both the independent, two-sided, two-sample t-test (Lecture 1) and dependent, two-sided, t-test for paired samples (Lectures 2 and 3) at the significance level of 5\% (0.05). In the pre- and post-test of the first lesson, the number of participants was 28 and 24, respectively. The results of the pre- and post-tests were recorded on each item only at the group level, which explains why we use the different t-test for this group. Concerning the following lessons, we compared the means of the test results on each item at the individual level. The second group (18/18 students) consists of both engineering and teacher students and the third group (39/39 students) only of engineering students. Tables 1 and 2 show the results of the analyses.

Table 1

The quantitative results of the pre-and post-tests (unpaired t-test) of the first lecture.

\begin{tabular}{cccccc}
\hline Problem no. & $\begin{array}{c}\text { Learning } \\
\text { study no. }\end{array}$ & $\begin{array}{c}\text { Pre-test } \\
\text { mean }\end{array}$ & $\begin{array}{c}\text { Post-test } \\
\text { mean }\end{array}$ & $p$ & $\begin{array}{c}\text { Maximum } \\
\text { scores }\end{array}$ \\
\hline $1 \mathrm{a}$ & 1 & 0.93 & 1.00 & 0.16 & 1 \\
$1 \mathrm{~b}$ & 1 & 1.07 & 1.00 & 0.67 & 2 \\
2 & 1 & 0.43 & 0.46 & 0.88 & 3 \\
3 & 1 & 0.68 & 0.88 & 0.59 & 3 \\
4 & 1 & 1.54 & 1.75 & 0.60 & 3 \\
5 & 1 & 0.00 & 0.00 & 0.91 & 3 \\
6 & 1 & 0.04 & 0.25 & 0.18 & 3 \\
\hline
\end{tabular}


In Table 1, we see that there are no statistically significant differences in learning results concerning the first lecture. The results related to the second and third lectures are given together in Table 2.

As Table 2 shows, the third lecture seems to have succeeded best: statistically significant improvements happened in many test items. The students' scores in question $1 \mathrm{a}$ ) and b) show that the students' intuitive understanding about the definite integral concept as an infinite process was quite good already at the beginning like their capacity to apply the additive property of definite integrals.

Almost all students failed to give an adequate response to question 5; most of them could not even find any errors at all. In Question 6, a majority of students could not discern which of the functions represented upper and lower functions or that how to determine the intersection points between the functions or how to calculate with fractions or how to give an exact answer.

Table 2

The quantitative results of the pre-and post-tests (paired t-test) of the second and third lectures.

\begin{tabular}{|c|c|c|c|c|c|}
\hline Problem no. & $\begin{array}{l}\text { Learning } \\
\text { study no. }\end{array}$ & $\begin{array}{c}\text { Pre-test } \\
\text { Mean }\end{array}$ & $\begin{array}{c}\text { Post-test } \\
\text { mean }\end{array}$ & $\mathrm{p}$ & $\begin{array}{c}\text { Maximum } \\
\text { scores }\end{array}$ \\
\hline \multirow{2}{*}{$1 \mathrm{a}$} & 2 & 0.94 & 1.00 & 0.33 & \multirow{2}{*}{1} \\
\hline & 3 & 0.92 & 1.00 & 0.08 & \\
\hline \multirow{2}{*}{$1 b$} & 2 & 1.11 & 1.11 & 1.00 & \multirow{2}{*}{2} \\
\hline & 3 & 0.82 & 0.82 & 1.00 & \\
\hline \multirow{2}{*}{2} & 2 & 0.83 & 0.44 & 0.09 & \multirow{2}{*}{3} \\
\hline & 3 & 0.51 & 0.97 & $0.00 *$ & \\
\hline \multirow{2}{*}{3} & 2 & 1.44 & 0.33 & $0.00 *$ & \multirow{2}{*}{3} \\
\hline & 3 & 0.13 & 0.92 & $0.00 *$ & \\
\hline \multirow{2}{*}{4} & 2 & 1.28 & 1.28 & 1.00 & \multirow{2}{*}{3} \\
\hline & 3 & 0.38 & 1.12 & $0.00 *$ & \\
\hline \multirow{2}{*}{5} & 2 & 0.00 & 0.00 & -- & \multirow{2}{*}{3} \\
\hline & 3 & 0.00 & 0.46 & $0.01 *$ & \\
\hline \multirow{2}{*}{6} & 2 & 0.78 & 0.28 & $0.02 *$ & \multirow{2}{*}{3} \\
\hline & 3 & 0.10 & 0.31 & $0.02 *$ & \\
\hline
\end{tabular}

$---=p$-value could not be calculated (Minitab: all values in column are identical, $* p<0.05$

\section{Discussion}

The purpose of this study was to find out whether university students' learning can be supported by finding suitable teaching sequences that help students to discern and experience mathematical concepts from the meaningful points of view. Experiencing variations of 
critical features of the object of learning should be, by the variation theory, a primary factor in enhancing students' learning (Marton \& Booth, 1997; Marton \& Morris, 2002).

In our study, two university teachers taught the definite integral concept for three student groups on an introductory course in calculus. Two of the lectures were prepared and planned with extraordinary care, taking into account the results from the written pre- and post- tests. Although the study consisted only of three lectures, it revealed that different teaching approaches had a significant influence on that how students' learning outcomes developed during the lectures.

We succeeded best in designing teaching sequences of the definite integral concept when we used the GeoGebra software. We interpret this being mainly due to the fact that GeoGebra is an effective tool for the illustration of dynamic processes, e.g., the limiting process of Riemann sums, and it allows a learner to experience simultaneously many critical aspects, e.g., how the area and the value of the definite integral are effected when the interval is modified. Also earlier research (i.e., Leung, 2003) shows that GeoGebra is a suitable pedagogical tool in creating the patterns of variation.

It is worth noticing that it did not provide a remarkable aid in Question 6 (although the difference between the mean scores of the pre- and post-tests improved for the third group in a statistically significant way). A plausible explanation is that GeoGebra or any other software cannot be used to compensate the lack of fundamental arithmetic skills although it often helps us to bypass challenging calculations and focus on the conceptual understanding of a mathematical problem.

In this study, we observed three critical aspects of the definite integral that seem to be important for the successful teaching of this concept and, consequently, for the design of the relevant patterns of variations. All these aspects can be discussed using GeoGebra.

First, it is important to consider the definite integral as a real number (i.e. the result of a limiting process) in a wider context and separate it from seeing it only as an area. This aspect was not elaborated during the first lecture - which can also be seen in the results of Tables 1 and 2. The use of GeoGebra during the third lecture seemed to extend students' possibilities to experience the concept of the definite integral in this wider context.

In the teaching sequences related to Figures 7 and 8 , the students were given opportunities to experience an effective contrast, i.e., to discern the definite integral not only as an area but, simultaneously, also as a real number. This allowed them to experience a generalization, that is to say, to experience that the definite integral can be a negative number, zero or a positive number.

Second, in spite of many efforts, it is plausible that many students' concept images of the definite integral will be based on the area interpretation (cf. Blum, 2000) and Tall and Vinner (1981). To change this, it may require a thorough revision of mathematics textbooks in school since they seem to emphasize this aspect. It is hard for an individual teacher to resist such a tradition but as our third lecture verifies, it is possible in a technological environment.

Third, the results also indicated that most students have difficulties in applying the Fundamental Theorem of Calculus, especially when the assumptions of the theorem are not satisfied. During the first lecture, the theorem was only mentioned quite superficially. On other lectures, the issue was given more attention; both examples and counter examples were elaborated. In the teaching sequence particularly related to Figure 9, the students were given 
an opportunity to experience a separation and a fusion. In order to experience a specific aspect - when it is not possible to apply the Fundamental Theorem of Calculus - and in order to separate this aspect from other aspects, the aspect must be varied while other aspects must remain constant.

In our teaching sequence, we kept the length of the interval and the functions $f(x)$ and $g(x)$ invariant and by moving the point $a$ along the $x$-axis we could vary the position of the investigated interval. The same sequence again gave the students an opportunity to experience the pattern of variation called fusion, i.e. if there are several critical aspects as 'it is possible to apply the Fundamental Theorem of Calculus', 'it is not possible to apply the Fundamental Theorem of Calculus', 'the function is defined and continuous in the closed and bounded interval', 'the function is not defined and continuous in the closed and bounded interval' and so on, they must all be experienced simultaneously.

The students' learning outcomes in Question 5 show that their conceptions of the conditions for applying the theorem were not changed after the second lecture. Only after the GeoGebra-based teaching sequence we could notice some statistically significant improvements of their results. We agree with Vinner (1991) that the students should be trained to use definitions as an ultimate criterion in mathematical issues in teaching and learning of mathematics. The students even mentioned in interviews that theorems were not discussed from the theoretical point of view; they were used as formulas. Students use procedures without considering definitions and theorems when solving problems. In order to develop a deeper understanding about the definite integral concept it is therefore important that the varying aspects of mathematical concepts are illuminated by using both examples and non-examples of the concepts in teaching of mathematics.

Yet another critical aspect we found is that students' poor arithmetic skills (Question 6) prevent them from gaining a deeper conceptual understanding about mathematical phenomena. Varying methods in order to solve this type of problem were applied during the second and third lecture but with a vanishing effect.

All in all, we are not very satisfied with the students' learning outcomes in this study. Further studies need to be undertaken to identify which other factors than the integration of technology and the LS model in the teaching and learning of mathematics can benefit both mathematics educators and students. It must be stressed once again that teaching and learning are very complex phenomena and the relation between them is not 'one to one'. In a teaching experiment like this, it would also be important to analyse what happens in the classroom in the interaction between the teacher and the students and between the students. Not even a good design of a lecture guarantees students' learning but it can increase possibilities for learning if students' conceptions and misconceptions of mathematical concepts are taken into account.

Finally, the study gave us a rare opportunity to collaborate with colleagues teaching and preparing a lecture. It was a rewarding experience to reflect and analyse students' learning together. We all agree that the LS model and the Variation Theory are effective tools for developing the teaching of mathematics and they provide a useful tool for increasing the teachers' awareness of the critical aspects of students' learning and enhancing the learning of mathematics in higher education. 


\section{References}

Adams, R. A. (2006). Calculus a complete course. Toronto: Addison Wesley.

Artigue, M. (2001). What can we learn from educational research at the university level? In D. Holton (Ed.), The teaching and learning of mathematics at university level: An ICMI study (pp.207-220). Dordrecht: Kluwer Academic Publishers.

Attorps, I. (2006). Mathematics teachers' conceptions about equations. Doctoral dissertation, Research Report 266. Department of Applied Sciences of Education, University of Helsinki, Finland.

Attorps, I., Björk, K., Radic, M., \& Tossavainen, T. (2010). The learning study model and the teaching of the definite integral concept. In M. Asikainen, P. E. Hirvonen, \& K. Sormunen (Eds.), Reports and Studies in Education, Humanities, and Theology, 77-86. University of Eastern Finland, Joensuu, Finland.

Barton, B., \& Thomas, M. (2010). Editorial. CULMS Newsletter, 1.

Burton, L. (1989). Mathematics as a cultural experience: Whose experience? In C. Keitel, P. Damerow, A. Bishop \& P. Gerdes (Eds.), Mathematics education and society - Science and Technologhy Education (Document Series 35, pp.16-19). Paris: Unesco.

Blum, W. (2000). Perspektiven für den Analysisunterricht. Der Mathematikunterricht, $46(4 / 5), 5-17$.

Booth, S. A. (1992). Learning to program: A pehenomenographic perspective. Göteborg Studies in Educational Sciences, 89. Göteborg: Acta Universitatis Gothoburgensis.

Brown, A. L. (1992). Design experiments: Theoretical and methodological challenges in

creating complex interventions in classroom settings. The Journal of the Learning Sciences, 2(2), 141-178.

Calvo, C. (1997). Bases para una propuesta didáctica sorbe integrales. Unpublished Master Thesis.

Camacho, M., Depool, R. \& Santos-Trigo, M. (2010). Student's use Derive software in comprehending and making sense of definite integral and area concepts. CBMS Issues in Mathematics Education, 16, 29-62.

Cobb, P., Confrey, J., diSessa, A., Lehrer, R., \& Scauble, L. (2003). Design experiments in educational recearch. Educational Researcher, 32(1), 9-13.

Collins, A.(1992). Towards a design science of education. In E. Scandlon \& T. D. Shea (Eds.), New directions in educational technology. Berlin: Springer.

Emanuelsson, J. (2001). En fråga om frågor. Hur lärarens frågor $i$ klassrummet gör det möjligt att få reda på elevernas sätt att förstå det som undervisningen behandlar $i$ matematik och naturvetenskap. Göteborg Studies of Educational Sciences. Göteborg: Acta Universitatis Gothoburgensis. 
Gustavsson, L. (2008). Att bli bättre lärare. Hur undervisningsinnehållets behandling blir till samtalsämne lärare emellan. Högskolan i Kristianstad, sektion för lärarutbildningen.

Häggström, J. (2008). Teaching systems of linear equations in Sweden and China: What is made possible to learn? Göteborg Studies of Educational Sciences. Göteborg: Acta Universitatis Gothoburgensis.

Leung, A. (2003). Dynamic geometry and the theory of variation. In N. Pateman, B. J. Doughherty, \& J. Zillox, Proceedings of the 27th International Conference for the Psychology of Mathematics Education (Vol. 3, pp.197-204). Honolulu: University of Hawaii.

Lewis, C. (2002). Lesson study: A handbook of teacher-led instructional change. Philadelphia: Research for Better Schools Inc.

Machín, M. C., \& Rivero, R. D. (2003). Using DERIVE to understand the concept of definite integral. International Journal for Mathematics Teaching and Learning, 4, 1-16.

Marton, F. (1993). Phenomenography. In T. Husén \& T. N. Postlethwaite (Eds.). The International Encyclopaedia of Education ( $\left.2^{\text {nd }} \mathrm{Ed}\right)(\mathrm{pp} .4424-4429)$. Oxford: Pergamon.

Marton, F., \& Booth, S. (1997). Learning and awareness. Mahwah, N.J.: Law Earlbaum.

Marton, F., \& Morris, P. (Eds.) (2001). What matters? Discovering critical conditions of classroom learning. Göteborg Studies of Educational Sciences. Göteborg: Acta Universitatis Gothoburgensis.

Marton, F., Runesson, U., \& Tsui, A. (2004). The space of learning. In F. Marton and A. Tsui (Eds.), Classroom discourse and the space of learning (pp. 3-40). New Jersey: Lawrence Erlbaum Associates, INC Publishers.

Marton, F., \& Tsui, A. (2004). Classroom discourse and the space of learning. Mahwah, NJ: Lawrence Erlbaum.

Orton, A. (1983). Student's understanding of integration. Educational Studies in Mathematics, 14(1), 1-18.

Pang, M. F., \& Marton, F. (2003). Beyond "lesson study": Comparing two ways of facilitating the gasp of some economic concepts. Instructional Science, 31, 175-195.

Rasslan, S., \& Tall, D. (2002). Definitions and images for the definite integral concept. In A. Cockburn \& E. Nardi (Eds.), Proceedings of the 26th International Conference for the Psychology of Mathematics Education (Vol.4, pp.89-96). Norwich, UK.

Rovio-Johansson, A., \& Johansson, I-L. (2005). Lärandets kontextualitet: Hur utvecklas ekonomstudenters förståelse av ett grundläggande ekonomiskt begrepp under utbildningen? Didaktiskt Tidskrift, 16(2-3), 61-92.

Runesson, U. (1999). Variationens pedagogik. Skilda sätt att behandla ett matematiskt innehåll. Göteborg Studies of Educational Sciences. Göteborg: Acta Universitatis Gothoburgensis. 
Rösken, B., \& Rolka, K. (2007). Integrating intuition: The role of concept image and concept definition for students' learning of integral calculus. The Montana Mathematics Enthusiast, 3, 181-204.

Sfard, A. (1991). On the dual nature of mathematical conceptions: Reflections on processes and objects as different sides of the same coins. Educational Studies in Mathematics, 22, $1-36$.

Stigler, J. W., \& Hiebert, J. (1999). The teaching gap. New York: The Free Press.

Tall, D. (1994). The transition to advanced mathematical thinking. Functions, limits, infinity and proof. In D. A. Grouws (Ed.), Handbook of research on mathematics teaching and learning (pp. 390-419). New York: Macmillan.

Tall, D., \& Vinner, S. (1981). Concept image and concept definition with particular reference to limits and continuity. Educational Studies in Mathematics, 12, 151-169.

Tossavainen, T., Haukkanen, P., \& Pesonen, M. (2013). Different aspects of monotonicity. International Journal of Mathematical Education in Science and Technology. doi:10.1080/0020739X.2013.770088.

Touval, A. (1997). Investigating a definite integral - from graphing calculator to rigorous proof. Mathematics Teacher, 90(3), 230-232.

Vinner, S. (1991). The role of definitions in teaching and learning. In D. Tall (Ed.). Advanced mathematical thinking (Chapter 5, pp.65-81). Dordrecht: Kluwer Academic Publishers.

Viirman, O., Attorps, I., \& Tossavainen, T. (2011). Different views - Some Swedish mathematics students' concept images of the function concept. Nordic Studies in Mathematics Education, 15(4), 5-24.

\section{Authors}

Iiris Attorps, Associate Professor, Ph.D., Faculty of Engineering and Sustainable Development University of Gävle, Sweden; ias@ hig.se

Kjell Björk, University Lecturer, MSc, Faculty of Engineering and Sustainable Development University of Gävle, Sweden; kbk@ hig.se

Mirko Radic, University Lecturer, Ph.D., Faculty of Engineering and Sustainable Development University of Gävle, Sweden; $\underline{\text { mrc@ @ig.se }}$

Timo Tossavainen, Associate Professor, Ph.D., School of Applied Educational Science and Teacher Education, University of Eastern Finland, Finland; timo.tossavainen@uef.fi 